\title{
A PROPÓSITO DEL BICENTENARIO DE LA INDEPENDENCIA NACIONAL PAPEL DE LOS CORSARIOS, PIRATAS Y MERCENARIOS EN LA INDEPENDENCIA DEL PERÚ
}

\author{
A PURPOSE OF THE BICENTENARY OF NATIONAL INDEPENDENCE ROLE OF \\ THE CORSARIES, PIRATES AND MERCENARIES IN THE INDEPENDENCE \\ OF PERU \\ Ricardo Bustamante Abad', Carmen Pablo Agama', \\ Manuel Changana García ${ }^{1}$, Riss Paveli García Grimaldo ${ }^{1}$
}

\section{RESUMEN}

Objetivo: Determinar en qué medida los corsarios, piratas, agentes secretos y mercenarios, contribuyeron decididamente en la independencia del Perú. Materiales y Métodos: La investigación se realizó en una muestra de 50 alumnos de la carrera de Ciencias Sociales de la Facultad de Educación de la Universidad Nacional José Faustino Sánchez Carrión 20 alumnos del V ciclo y 30 del VI ciclo. Resultado: La ofensiva realista alcanzó su máximo, según podemos observar, alrededor de 1815-1816 obtuvo numerosas victorias, pero no consiguió denotar del todo a los partidarios de la independencia que fueron preparando lo que habría de ser la contra ofensiva final en su favor con las campañas de San Martín y Bolívar en Chile, Perú (Macera, Pablo. 1986). Conclusiones: Poco después de la entrada triunfal en Santiago, San Martín, con la excusa de negociar el canje de prisioneros, envió a Lima al mayor Domingo Torres. El agente del libertador llevaba 6 mil pesos destinados a socorrer la situación desesperante en la que se encontraban los presos patriotas en las mazmorras del Callao. Habían caído en las guerras españolas tras los combates de Chile (Chacabuco y Cancha Rayada) y en las diferentes campañas al Alto Perú (Pigna Felipe. 2014).

Palabras clave: Corsario, Pirata, Agente Secreto, Independencia.

\begin{abstract}
Objetive: Determine the extent to which privateers, pirates, secret agents and mercenaries, contributed decisively in the independence of Peru. Material And Methods: The research was carried out in a sample of 50 students from the Social Sciences department of the Faculty of Education of the José Faustino Sánchez Carrión National University, 20 students from the 5th cycle and 30 from the 6th cycle. Result: The realistic offensive reached its maximum, as we can see, around 1815-1816 won numerous victories, but failed to fully denote the supporters of independence who were preparing what would be the final counter offensive in their favor with the campaigns of San Martín and Bolívar in Chile, Peru (Macera, Pablo, 1986). Conclusion: Shortly after the triumphal entry into Santiago, San Martin, with the excuse of negotiating the exchange of prisoners, sent Major Domingo Torres to Lima. The agent of the liberator carried 6 thousand pesos destined to help the desperate situation in which the patriotic prisoners were in the dungeons of Callao. They had fallen in the Spanish wars after the combats of Chile (Chacabuco and Cancha Rayada) and in the different campaigns in Upper Peru (Pigna Felipe, 2014).
\end{abstract}

Keywords: Corsair; Pirate; Secret Agent; Independence.

${ }^{1}$ Facultad de Educación. Universidad Nacional José Faustino Sánchez Carrión. Lima-Perú Email: vinvestigacion@unjfsc.edu.pe 


\section{INTRODUCCIÓN}

No hubiera sido posible los cambios sintomáticos, si don José de San Martín no hubiera contado con los servicios de una red de agentes secretos, corsarios, piratas y mercenarios. El primero de ellos ocurrió con la expedición Brown (1815-1817) al mando del marino inglés Guillermo Brown, que tenía el grado de corsario, así como Bouchard y Lord Cochrane, etc.

\section{EL CRUCERO DE BROWN (1816-1817)}

Decía San Martín "Convénzanse, hasta que no estemos en Lima, la guerra no terminará", de allí su decisión de cruzar la cordillera de los Andes y llevar la guerra al Pacífico. Mientras tanto, el Océano Pacífico era escenario de acontecimientos indirectamente ligados con la guerra de la independencia (Macera, Pablo. 1985.). El gobierno argentino, interesado en promover la insurrección chilena, pensó en utilizar una expedición naval, hasta tanto los exhaustos fondos del tesoro permitieron organizar una campaña en regla. El corsario Guillermo Brown vencedor de los realistas fue escogido por San Martín para incursionar hacia el Callao y avanzaron soportando el tenaz fuego cruzado de las baterías españolas.

La nave Hércules se dirigió para liberar a los prisioneros patriotas del presidio. Una tormenta procedente del Sur rompió el baupres del barco al acercarse a la isla y la arrastró hacia el Callao. El "Santísimo Trinidad" y la "Halión" navegaron juntos en dirección Norte sin acercarse a la costa hasta el punto de reunión convenido con la fragata "Hércules" en la cercanía del Callao.

Brown y sus marinos atacaron a las naves españolas generando alarma en toda la costa peruana. Cerca de la isla denominado "MOCHA" capturaron y hundieron a la goleta enemiga "MERCEDES" que había venido de CHILE, con respecto a la carga y los marinos fueron destinados a la expedición (Felipe Pigna. 2014).

El 10 de enero de 1816 los barcos se reunieron en los farallones de las Hormigas, al Norte de Callao. El 11 de enero apresaron al bergantín "SAN PABLO" que había partido del Callao, al cual convirtieron en PONTÓN para depositar víveres y prisioneros y para alojar a los enfermos del escorbuto. El 12 de enero capturaron a la fragata "Gobernadora" que llegaba al Callao proveniente de Guayaquil con un cargamento de cacao y cera.

En ella era conducido prisionero del Callao el Teniente Coronel Vicente Venegas, oficial del ejército republicano de Nueva Granada; quien se sumó a la expedición. El 18 de enero capturaron cuatro embarcaciones: la goleta "Carmen", el bergantín "Místico" y dos naves más, una de ellas fue saqueada y hundida.

Algunos prisioneros que fugaron de los farallones de las Hormigas avisaron al subdelegado del partido de Chancay, quien avisó al Virrey José Fernando de Abascal y Sousa en Lima. El Virrey desplegó rápidamente una serie de medidas defensivas para evitar el proyectado ataque por sorpresa a los barcos del Callao.

Los destacamentos de caballería de milicias que custodiaban la costa fueron reforzados con partidas de
Húsares y de dragones y la guarnición del Callao fue intensificada. Las naves fueron organizadas bajo protección de las baterías costeras. Destacó una goleta en la isla de Juan Gallán para que rápidamente pudiera dar aviso a los barcos que se acercasen sin saber la presencia de corsarios.

El 20 de enero se reunieron una asamblea los comerciantes criollos de Lima y donaron 200 mil pesos para equipar una escuadrilla de barcos y pueda hacer frente a los corsarios. De esta manera una junta de 5 comerciantes se preparó para la defensa marítima del virreinato del Perú.

El día 21 de enero los corsarios se apostaron en la boca del puerto y lanzaron salvas de artillería saludando a la bandera argentina. Durante la noche se acercaron al puerto y dispararon varios cañonazos sobre la costa y los barcos. Por la noche hundieron la fragata "FUENTE HERMOSA".

El 22 de enero el corsario Brown se apoderó del puerto, pero en el puerto no había ninguna lancha cañonera, ni buque armado. Sus fortalezas eran constituidas de cuatro buques y un pailebot. Tres flotas de Brown se adelantaron hasta fondear en la misma bahía y estas cañonearon por si pudiera dar en el blanco de las flotas enemigas, sin embargo, los enemigos respondieron desde los castillos del Callao, volvieron a levar anclas y así estuvieron disparando hasta la medianoche, hora en que las huestes de Mr. Brown liberaron a los prisioneros en la isla San Lorenzo y continuaron los días siguientes en la bahía del puerto del Callao infundiendo alarma y temor (Macera. 1988).

El 27 de enero el capitán CHITTY y sus hombres mandados por Mr. Brown se embarcaron en cinco botes y se trabó en una sangrienta acción con los marinos realistas a punta de balas y bayonetas, siendo obligados a huir en la inmensidad de la noche.

El 28 de enero, los hombres del Brown apresaron dos importantes presas, las fragatas "Candelaria" y "Consecuencia", estas naves arribaban procedente de Cádiz viajando a bordo el brigadier Juan Manuel de MENDÍBURO, este personaje iba a tomar el cargo de Gobernador de Guayaquil, finalmente fue apresado por los corsarios y Mr. Brown. La nave "Candelaria" viajaba de Chile al Perú y fue transformada en buque corsario, según (Macera. 1998) el buque poseía 6 cañones de a 12 libras y 175 tripulantes.

INCURSIÓN DEL CORSARIO BROWNA GUAYAQUIL

Según el plan diseñado por don José de San Martín el corsario Brown, decidió el 29 enero partir hacia el Norte posesionándose el 6 de febrero del puerto de Guayaquil. Por orden del corsario Mr. Brown los prisioneros de rango inferior fueron desembarcados en la isla denominada del "Muerto" y las naves alinearon el 7 de febrero en la isla Puná y según Brown desde ese lugar buscaba intimar la rendición de la ciudad.

Sin embargo, Juan Vasco y Pascual, gobernador de Guayaquil, habían sido alertados por los comerciantes de Lima sobre el accionar del corsario Mr. Brown por lo que tomó las medidas defensivas. El gobernador ordenó la reunión de milicias y reforzó las guarniciones de los fuertes, internó además los barcos cerca de la costa. 
EL 8 de febrero arribó al puerto un pailobot dirigido por José Villamil, comunicado que había sido perseguido por los piratas que se hallaba en Puná.

Mr. Brown ordenó a sus hombres permanecer fondeados para proteger a la tripulación, mientras tanto se embarcó en la nave "Santísima Trinidad", con la que atacó y se posesionó de Guayaquil. Poco después incursionó en el rio Huayas con la nave "Santísima Trinidad", acompañado de la goleta "Nuestra Señora del Carmen" y además fueron reforzados con la tropa de "Halcón", que le permitió llegar al canal de "JAMBELI".

Al día siguiente cruzaron fuego con la fortaleza de punta de Piedra, ubicada a 5 leguas de Guayaquil y armada con 12 cañones y una escasa guarnición a la que tomaron y demolieron. Asimismo, el día 9 de febrero atacaron y se posesionaron de una batería de 4 cañones, ubicada a media legua de Guayaquil, reduciendo y capturando 10 prisioneros luego de desembarcar tropas que destruyeron los cañones.

Los corsarios (Macera Pablo. 1986) se dirigieron a atacar al fuerte de San Carlos, último fuerte antes de llegar a la ciudad que contaba con una guarnición de 50 hombres. Mr. Brown intentó acercarse a "Tiro de pistola" de la batería de dos cañones ubicada a una milla de la ciudad, que al mando de Juan Ferruyola hacía fuego sostenido sobre sus naves, sin embargo Mr. Brown insistió y ordenó el ataque haciendo que el buque encallara.

Es entonces que la nave es abordada por milicianos realistas que remataron a los heridos, ante esta situación Mr. Brown se dirige con una mecha encendida, amenazando con volar a la nave sino se detenía la matanza, la cual en gran parte consiguió, ya que el armador Manuel Jado se hizo llevar a bordo e hizo cesar el combate, Mr. Brown hizo bajar a tierra al capitán de la nave "CONSECUENCIA", para exigir garantía para él y sus hombres, amenazando con un sangriento ataque de los demás barcos corsarios, si fueran asesinados.

Los corsarios avanzaron resueltos a destruir la ciudad si no conseguían un canje de prisioneros. Las autoridades y las fuerzas vivas de la ciudad el día 11 de febrero en un cabildo abierto acordaron no escuchar ninguna proposición de los corsarios, sin embargo, ante el eminente peligro de un ataque destructor, aceptaron las negociaciones que consistió en el canje de Mr. Brown por la fragata "CANDELARIA" más tres bergantines y así mismo se acordó el canje de prisioneros y el rescate de la fragata denominada "GOBERNADORA" por 22 mil pesos.

Los corsarios al retirarse se llevaron las fragatas "HÉRCULES" y "CONSECUENCIA", también la corbeta "HALCÓN" y la goleta "CARMEN", así el 27 de febrero los buques corsarios abandonaron el Puerto de Guayaquil. De esta manera se dejó el campo libre para la incursión eminente de la empresa libertadora del Sur, dirigido por el general don José de San Martín.

\section{PARTICIPACIÓN DEL FRANCÉS HIPÓLITO} BOUCHARD EN LAINDEPENDENCIADEL PERÚ

Hipólito Bouchard fue corsario que estuvo al servicio de San Martín. Su misión era atacar puertos y barcos españoles en América y las Filipinas. Estas acciones se desarrollaron entre julio de 1817 y julio de 1819, precisamente cumple 200 años, estas titánicas luchas por la independencia del Perú e Hispanoamérica.

Bouchard (Macera Pablo) circunnavegó el planeta comandando operaciones de corso, combates en las costas de Indonesia, Hawai, México y Centroamérica, pero en Chile es apresado por cargos de piratería. Comandó la nave de "La Argentina" y que obtuvo 26 presas y más de 10 acciones militares.

\section{HIPÓLITO BOUCHARD Y LOS GOBIERNOS INDEPENDIENTES}

Conforme los países hispanoamericanos se independizaban colaboraron en la quiebra del poder monopólico de España, es así que buscaron dañar el comercio marítimo de la corona española y propagandizar la guerra marítima en los territorios dominados por los españoles.

Para este fin se valieron de corsarios piratas, que permitía armar bajo su bandera a naves privadas y atacar a barcos españoles, sin comprometer a los Estados independientes y así ahorrar recursos del Estado. Mediante esta forma de organización los corsarios y piratas obtuvieron 15 barcos como presas entre los años de 1814,1823.

Bouchard, obtuvo patente de corso, por el gobierno de Buenos Aires en la que se celebró un contrato llamado "PATENTE DE CORSO" con dicho documento Bouchard tenía el $V^{\circ} \mathrm{B}^{\circ}$ de atacar, apresar, saquear y destruir buques españoles, quedándose según el contrato una parte del botín obtenido.

INCURSIÓN DE LA EXPEDICIÓN DE HIPÓLITO BOUCHARD EN LAS AGUAS DEL OCÉANO PACÍFICO

Hipólito Bouchard fue ascendido a Sargento Mayor de marina por el gobierno de Argentina y para cumplir con el objetivo de destruir las naves españolas, solicitó una moderna nave que le dieron el nombre de "LA ARGENTINA". La referida nave era de importante tamaño con 464 toneladas de desplazamiento con respecto a los armamentos, el gobierno de Buenos Aires le proporcionó 34 piezas de artillería, 18 cañones, 128 fusiles, 800 balas de cañón.

Bouchard además pidió 40 sables de caballería, sin embargo, el gobierno de Buenos Aires no contaba con esa cantidad. Con respecto a la tripulación se necesitaba no menos de 180 hombres, aunque fue muy difícil de encontrar tal cantidad, ya que Bouchard se había ganado la fama de ser un marino muy disciplinado y fuerte, después de muchas semanas logró copar tal necesidad. Conformado la mayor parte por extranjeros, muchos de ellos europeos como Nataniel SOMMERS, WILLIAM SHEPPARD, COLVERT, TOMPSON, Daniel Oliver, Williams Mills y LOUIS GREISSAC y otros.

Además, Bouchard solicitó el uso del uniforme de la marina de guerra, todo esto nos dice (Macera, Pablo) como una cuestión de motivación, orden y el respeto. Asimismo, los marinos eran extranjeros de origen europeo, aunque mucho de ellos genuinos oriundos de Buenos Aires. 


\section{ZARPAMIENTO DE LAEXPEDICIÓN BOUCHARD}

Según PIGNA Felipe el 27 de junio de 1817 Bouchard recibió la patente de corso $\mathrm{N}^{\circ} 116$, expedido por el Director Supremo PUEYRREDÓN, es así que el 9 de julio de 1817 primer aniversario de la Declaración de la Independencia de Argentina, la nave "La Argentina" zarpó desde la ensenada de Barragán que había de durar dos años.

Bouchard tomó la ruta del Océano Atlántico en busca de los navíos de la Real Compañía de Filipinas que est4aban al servicio de España, allí descubrió que naves británicas estaban al servicio de España, por lo que Bouchard ordenó que los cañones apuntasen a los barcos enemigos e inmediatamente hizo liberar a los esclavos y de la misma manera que se apoderó de los alimentos de los buques esclavistas.

Después de este hecho Bouchard enrumbó con la nave "La Argentina" con la finalidad de atacar los buques españoles que merodeaban por la región. Durante ese trayecto la tripulación se vio afectado por el escorbuto, debido a las deficiencias en el consumo de alimentos frescos, a tal punto que según el diario de a bordo y llegando al tener 100 enfermos a la vez, pese a todo "La Argentina" siguió navegando rumbo a las islas Filipinas, resistiendo varias tempestades que lo acompañaron hasta el estrecho de Sonda, que separa las islas de Java y Sumatra.

El 7 de noviembre Bouchard decidió fondear en la isla Nueva de la cabeza de Java para que los enfermos pudieran ser atendidos. Muchos fueron alojados en tiendas de campaña, sin embargo luego de 8 días no lograban recuperarse por lo que el médico aconsejó que fueran enterrados hasta el cuello, método que aceleró la curación de muchos enfermos. El escorbuto cobró la vida de unos 40 tripulantes de "La Argentina".

\section{BOUCHARD SE ENFRENTA A LOS PIRATAS MALAYOS}

Bouchard, dejó la isla de Java continuando el viaje hacia las Filipinas, había perdido 40 hombres y muchos de ellos fueron atacados de escorbuto y disentería. La zona era muy peligrosa, aunque se produjo un encuentro con algunos piratas en el estrecho de MACASAR y la lucha fue cuerpo a cuerpo, resultando 7 marinos de Bouchard heridos y a la hora y media de fuego y del golpe de las armas el capitán de la proa de los piratas, viendo frustrado sus designios decidió darse dos puñaladas y se arrojó al agua. De la misma manera hicieron otros cinco tripulantes.

Acto siguiente Bouchard, ordenó tomar el barco mientras el resto de los piratas huían. Poco después se posesionaron en la nave y encontraron 42 piratas, que fueron amarrados. El comandante convocó a un consejo de guerra para juzgar a los piratas que había capturado un barco portugués matando a todos sus tripulantes, por estos hechos el consejo de guerra fueron sentenciados a la pena de muerte, mientras que con los prisioneros fueron devueltos a su nave, Bouchard ordenó derribar los palos de la nave, acto seguido se procedió a cañonear la nave hasta hundirla.

BOUCHARD Y LAINDEPENDENCIADEL PERÚ
Bouchard decidió sumarse a la campaña de independencia del Pe4rú. Puso al servicio de la causa sus dos embarcaciones como transporte y le escribió a su armador solicitándole que ayudara económicamente a su familia. Aquí se dio inicio a las desavenencias con el señor Echevarría debido a que el corsario Bouchard se ausentó largo periodo, ocasionando pérdidas por concepto de reparaciones de las naves, es por ello cuando envió arcilla con una de las naves por concepto de 25 mil pesos el armador se apropió de la carga y el dinero.

Bouchard, en 1820 se encontraba en el Perú contratado por las marina chilena, bajo el mando de don José de San Martín y poseía el cargo del protectorado del Perú es por ello Bouchard le solicitó volver a "La Argentina" debido a la difícil situación económica que estaba pasando su esposa e hijos, pero el general San Martín le negó y más bien le exigió que permaneciera en Lima por espacio de 5 meses.

Bouchard, vivía angustiado y es por ello capturó en Pisco 2 naves españolas que poseía mercancías por valor de 95 mil pesos. Asimismo, Lord Cochrane se encontraba en las aguas peruanas en discrepancia con don José de San Martín por la cuestión de los caudales depositados en los buques de guerra que Cochrane pretendía cobrar los haberes adeudados.

Frente a esta difícil situación San Martín decidió combatir a Cochrane disponiendo la creación de la marina peruana, y puso a Hipólito Bouchard en el mando de la fragata "PRUEBA", la más relevante de la marina peruana.

Poco después el marino inglés Cochrane continuó sus reclamos respecto al pago de sus servicios marinos, pero Tomás Guido ordenó a Bouchard que estuviera a la expectativa y esté preparado en caso de que el marino Cochrane se dispusiera atacar por sorpresa, pero no lo hizo, posiblemente enterado que la nave peruana estaba bien pertrechada.

Bouchard continuó en aguas peruanas bajo el mando de San Martín, había logrado destruir todas las naves españolas y por ello la independencia del Perú y América estaba garantizada.

\section{MATERIAL Y MÉTODO}

La investigación se llevó a cabo en una muestra estratificada en 50 personas entre alumnos y docentes de la universidad nacional José Faustino Sánchez Carrión de Huacho, 20 alumnos de la especialidad de Ciencias Sociales y Turismo de la facultad de educación y 30 docentes de Ciencias Sociales y Turismo para integrar nuestra investigación en proceso de recolección, análisis de datos cuantitativos y cualitativos.

En el mismo estudio se hizo uso del enfoque mixto. Se utilizó estadística descriptiva básica y se realizaron comparaciones para describir las variables. Se entrevistaron a un total de 20 alumnos del $\mathrm{V}$ ciclo de la especialidad de ciencias sociales y turismo de la Facultad de Educación para saber si tenían información y conocimiento sobre el papel de los corsarios y piratas en la independencia del Perú. 
Tabla 1. Papel De Los Corsarios, Piratas Y Mercenarios En La Independencia Del Perú

\begin{tabular}{|c|c|c|c|c|c|c|c|c|c|c|c|c|c|}
\hline \multirow[t]{3}{*}{ ITEM } & \multicolumn{13}{|l|}{ VE } \\
\hline & & & 1 & & 2 & & 3 & & 4 & & 5 & & 6 \\
\hline & & $F$ & $\%$ & $\mathrm{~F}$ & $\%$ & $\mathrm{~F}$ & $\%$ & $\mathrm{~F}$ & $\%$ & $F$ & $\%$ & $F$ & $\%$ \\
\hline SI & 4 & 4 & 13.3 & 3 & 10.00 & 18 & 80.00 & 4 & 13.3 & 2 & 6.66 & 6 & 6.66 \\
\hline NO & 3 & 20 & 66.76 & 24 & 80.00 & 8 & 26.8 & 16 & 53.43 & 21 & 70.00 & 7 & 76.76 \\
\hline POCO & 2 & 3 & 10.00 & 1 & 3.43 & 2 & 6.6 & 6 & 20.00 & 7 & 23.43 & 1 & 13.33 \\
\hline MUCHO & 1 & 3 & 10.00 & 2 & 6.66 & 2 & 6.6 & 4 & 13.33 & - & 1 & 3 & 33.33 \\
\hline TOTAL & & 30 & 100.00 & 30 & 100.00 & 30 & 100.00 & 30 & 100.00 & 30 & 100 & 30 & 100.00 \\
\hline
\end{tabular}

Tabla 2. Interpretación Porcentual

\begin{tabular}{cccccccccc}
\hline ITEM & VE & & 1 & & $\mathbf{2}$ & & 3 & & 4 \\
& & $\mathrm{~F}$ & $\%$ & $\mathrm{~F}$ & $\%$ & $\mathrm{~F}$ & $\%$ & $\mathrm{~F}$ & $\%$ \\
\hline MUY BUENO & 4 & 2 & 10 & 1 & 5 & 3 & 15 & 13 & 65 \\
BUENO & 3 & 12 & 60 & 16 & 80 & 14 & 70 & 4 & 20 \\
REGULAR & 2 & 5 & 25 & 3 & 15 & 1 & 5 & 2 & 10 \\
MALO & 1 & 1 & 5 & - & - & 2 & 10 & 1 & 5 \\
TOTAL & 10 & 20 & 100 & 20 & 20 & 20 & 100 & 20 & 100 \\
\hline
\end{tabular}

Según el porcentaje de los entrevistados $6.66 \%$ indicó que, si conoce y sabe, el $76 \%$ no tiene información acerca de los corsarios, piratas de la independencia del Perú, el $13,33 \%$ señaló que poco sabía y el $3.33 \%$ respondió conocer y saber mucho.

Asimismo, se entrevistaron a un total de 30 docentes de la Facultad de Educación de la especialidad de Ciencias Sociales y Turismo para saber y conocer que, si sabían y conocían de los corsarios, piratas que participaron en la independencia del Perú.

Del porcentaje de los grupos entrevistados, el $65 \%$ considera muy bueno, el $20 \%$ bueno, el $10 \%$ regular y

\section{REFERENCIAS BIBLIOGRÁFICA}

Contreras, C. (2016). "Independencia: los antecedentes y el proceso (1818-1826). IEP.

Comisión Nacional Del Sesquicentenario De La Independencia Del Perú. Antología De La Independencia Del Perú. Lima. 1972.

Macera, P. (1988). "Historia del Perú”. Editorial Bruño.

Pigna, F. (2014). "La voz del gran jefe, vida y pensamiento de José de San Martín. Grupo Editorial Planeta. Buenos Aires.

Soria, D. (2004). "Las campañas militares del General San Martín. Instituto Nacional Sanmartiniano. Buenos Aires. el $5 \%$ malo, no conocen.

\section{DISCUSIÓN}

Este año 2017 se cumple los 200 años de la incursión de los piratas, corsarios y mercenarios en las aguas del mar peruano que jugaron un papel relevante en la independencia del Perú. Es por ello que el propósito de nuestra investigación es saber si los docentes y estudiantes de la Facultad de Educación de la Universidad Nacional José Faustino Sánchez Carrión estaban informados y sabían de estos aguerridos hombres que llegaron al Perú antes que el general don José de San Martín.

Los resultados indican que la mayoría de los docentes y estudiantes mostraron que no conocían a Mr. Brown ni Hipólito Bouchard, corsarios contratados que llegaron en 1817 con el fin de dejar el mar sin naves españolas, y de esta manera dejar el campo libre para que San Martín desembarcara sin mayores contratiempos en la bahía de Paracas con sus soldados y equipo militar.

De esta manera se cumplió este plan estratégico, así los patriotas como los realistas sabían bien que quien controlaba el mar tenía ganada la mitad de la guerra del Perú (Macera. 1988). Este era un conocimiento muy antiguo desde la época de los piratas y corsarios de los siglos XVI y XVII.

La expedición Brown de 1816, más tarde de Bouchard en 1817 que hemos tratado había demostrado la relativa debilidad de las fuerzas realistas en el mar del Perú. Pero también no existía entonces una escuadra patriota debidamente constituida para decidir la contienda. De allí que entre 1816-1817-1818 el Pacífico Sur entre Guayaquil y Arica fue teatro de operaciones no convencionales en la que intervinieron corsarios, piratas y mercenarios a favor de la causa patriota. 